\title{
Ovarian endometriosis: risk factor analysis and prediction of malignant transformation
}

\author{
YanNa Zhou', Ke-qin $\mathrm{Hua}^{2}$ \\ JinShan Branch of Shanghai No.6 People's Hospital, China \\ 2Obstetrics and Gynecology Hospital of Fudan University, China
}

\begin{abstract}
Introduction: For the prediction of endometriosis associated ovarian carcinoma (EAOC), the risk factors for malignant ovarian endometriosis (MOE) were explored.

Material and methods: A group of 104 EAOC patients was compared with a group of 104 ovarian endometrial cyst patients. Using single and multivariate risk analysis of EAOC by calculating the area under the curve (AUC) of receiver-operator characteristics (ROC) curves, risks of MOE transformation were calculated for various burdens of risk factors.

Results: The age range of 85 EAOC patients ( $81.73 \%$ of EAOC patients) was from 40 to 60 years old, as menopause occurs most frequently in this age range. From single factor ROC curve analysis, if disease duration/ age/menopause/times of pregnancy/multiple foci of endometriosis index AUC were above 0.70 , this suggested that the above indicators were predictive of MOE. Times of pregnancy/tumour size/myoma of uterus/multiple foci of endometriosis were taken as the independent risk factors of MOE. Using logistic regression, the AUC of 0.89 (95\% confidence interval [Cl]: 0.84-0.94) was statistically significant $(p<0.001)$, illustrating the predictive power of this model.

Conclusions: Times of pregnancy/BMI/irregular vaginal bleeding/thyroid disease/myoma of uterus/tumour serious fixation index indicate higher risk of MOE; age/tumour size/menopause/disease duration/dysmenorrhea/multiple foci of endometriosis suggest lower risk of MOE. Therefore, in patients with endometriosis, malignant transformation could be predicted early.
\end{abstract}

Key words: ovarian endometriosis, endometriosis associated ovarian carcinoma, prediction of malignant transformation.

\section{Introduction}

Endometriosis is a condition in which the layer of tissue that normally covers the inside of the uterus grows outside it. After Sampson et al. first reported the malignant transformation of ovarian endometriosis in 1925, there has been a lot of research into the subject. The most common location of malignant endometriosis is the ovary, known as "endometriosis-associated ovarian carcinoma" (EAOC). However, because the ovaries are located in the pelvic cavity with room to expand before detection, they are most commonly discovered at a later stage, with a poorer prognosis. Because early detection of malignant endometriosis can greatly increase the 5-year survival of patients with EAOC [1], early prediction, diagnosis, intervention, and treatment of EAOC are very important. Herein, we present our experiences with the early diagnosis and treatment of MOE in EAOC patients.

\section{Material and methods}

\section{Subjects}

This retrospective study, carried out between July 2008 and February 2015, recruited 104 patients with EAOC, who underwent surgery in JinShan Branch of Shanghai No. 6 People's Hospital and Department of Obstetrics and Gynaecology, Hospital of FuDan University into group 1, and 104 patients who were diagnosed with an ovarian endometriosis cyst and subsequently received surgery were used as a control sample, called group 2. All patients were without immune disease, metabolic disease, hypertensive disease, diabetes, and other gynaecological malignancies, and all patients did not receive hormone therapy. The two groups of patients were compared in terms of environmental exposure, living habits, and occupation, and the difference was not statistically significant $(p>0.05)$. 


\section{Material and methods}

\section{Diagnostic criteria}

MOE was diagnosed according to the diagnostic criteria of Sampson and Scott [2, 3]. The diagnosis is based on the following: 1) cancer tissues and ectopic endometrial tissue (EMT) coexist in the same lesion; 2) the cancer and EMT correlated; 3 ) there are no other related tumours; and 4) EMT malignancy progression is observed.

\section{Data collection and analysis}

The researchers filled in the answers using clinical record data from the hospital database of JinShan Branch of Shanghai No. 6 People's Hospital and Obstetrics and Gynaecology Hospital of Fudan University. A standardized questionnaire was used to obtain clinical data of patients in both groups. Data collected included: general physical information, menstrual history, reproductive history, other medical history, first symptoms, tumour size, history of uterine fibroids, pathological diagnosis, family history of cancer, gynaecological examination, auxiliary examination, and prognosis.

With the single- and multi-variate analysis, the clinical data of the two groups were compared. (Based on the risk factors, the ROC curve analysis and logistic risk prediction regression equations were used to assess the malignant transformation efficiency. The researchers had access to personal identifying information, and informed consent and the related study were conducted according to Declaration of Helsinki.

\section{Statistics}

SPSS 19.0 was used for statistical analysis. The qualitative indices were statistically described by frequency

Table 1. EAOC pathological type

\begin{tabular}{llc}
\hline $\begin{array}{l}\text { Malignant sites } \\
\text { and pathological types }\end{array}$ & Cases (\%) & $\begin{array}{c}\text { With endometrial } \\
\text { carcinoma }\end{array}$ \\
\hline Ovarian clear cell carcinoma & $57(54.81)$ & 7 \\
\hline $\begin{array}{l}\text { Ovarian endometrial } \\
\text { adenocarcinoma }\end{array}$ & $29(27.88)$ & \\
\hline $\begin{array}{l}\text { Advanced ovarian serous } \\
\text { adenocarcinoma }\end{array}$ & $8(7.70)$ \\
\hline $\begin{array}{l}\text { Borderline endometrial } \\
\text { adenocarcinoma with }\end{array}$ & $4(3.85)$ \\
$\begin{array}{l}\text { Squamous differentiation } \\
\text { Ovarian carcinoma sarcoma }\end{array}$ & $2(1.92)$ \\
\hline $\begin{array}{l}\text { Ovarian mucinous } \\
\text { adenocarcinoma }\end{array}$ & $1(0.96)$ \\
\hline $\begin{array}{l}\text { Ovarian endometrial } \\
\text { stromal sarcoma }\end{array}$ & $1(0.96)$ \\
\hline $\begin{array}{l}\text { Malignant juvenile } \\
\text { granulosa cell tumor }\end{array}$ & $1(0.96)$ \\
\hline Adult granulosa cell tumor & $1(0.96)$ \\
\hline Total & $104(100)$ \\
\hline
\end{tabular}

and rate, and the differences between groups were analysed by $\chi^{2}$ test or Fisher test. The quantitative indices were statistically described by mean and standard deviation, and the differences between groups were statistically described by $t$-test. The non-normal quantitative index (Q1, Q3) was used for statistical description, and the differences between groups calculated using the Wilcoxon test. Multivariate regression analysis was performed using a logistic regression equation and backward stepwise regression method, and the inclusion criteria of variables in statistics was in the range of 0.05 the diagnostic analysis was undertaken with ROC curve and two-sided $t$-tests, with a significance threshold at $p<0.05$.

\section{Results}

\section{Clinical characteristics}

\section{Disease incidence and pathology}

From July 2008 to February 2015, in JinShan Branch of Shanghai No.6 People's Hospital and Department of Obstetrics and Gynaecology Hospital of FuDan University, there were 104 EAOC and 6,468 ovarian endometriosis cyst patients. The ratio of malignant transformation was $1.61 \%$. Amongst 104 EAOC patients, there were 86 patients $(82.69 \%)$ with ovarian clear cell carcinoma and endometrial adenocarcinoma, and amongst 29 ovarian endometrial adenocarcinoma patients, there were $7 \mathrm{pa}$ tients with endometrial carcinoma. The number of other pathological types of MOE patients was 18 (17.31\%). More comprehensive statistical data is shown in Table 1.

\section{Age distribution}

The age distribution of 104 EAOC patients is shown in Fig. 1.

As can be seen in Fig. 1, there were 85 EAOC patients (81.73\%), the age range was 40 to 60 years old, and disease onset was around the time of menopause.

\section{Patient characteristics}

In a comparison of 26 research variables between the groups, there was no significant difference in cancer antigen 125 (CA125), the age of menarche, menstrual period, menstrual cycle, contraceptive method, application of hormone, delivery times, caesarean section, with endometrial carcinoma, with hypertension, and with diabetes mellitus. Statistically significant indicators are described in Table 2.

\section{Risk factor analysis and risk prediction of EAOC \\ Single factor logistic regression analysis}

The statistically significant variables in the two groups were taken as independent variables, the malignant or non-malignant state of ovarian endometrio- 
sis was taken as dependent variable, and the variables were analysed via non-conditional logistic regression. If the OR index of times of pregnancy, BMI, irregular vaginal bleeding, thyroid disease, myoma of uterus, and tumour serious fixation was above 2.0, this indicated increased risk of EAOC. If the AUC index of age, tumour size, menopause, disease duration, dysmenorrhoea, and multiple foci of endometriosis were above 0.7, this suggested they had predictive efficacy for MOE transformation. The ORs of each factor, AUCs, and $95 \% \mathrm{Cls}$ are shown in Table 3.

\section{Multivariate logistic regression analysis}

The statistically significant variables in the two groups were taken as independent variables, the malignant or non-malignant state of ovarian endometriosis was taken as dependent variable, and the variables were analysed via non-conditional logistic regression and the stepwise "backwards" method. The selected criteria were $<0.05$, exclusion criteria was $>0.05$; times of pregnancy, tumour size, myoma of uterus, and multiple foci of endometriosis were taken as the independent risk factors of $\mathrm{MOE}$, with the established logistic regression equation. The regression coefficients of each factor are shown in Table 4, logistic regression equation

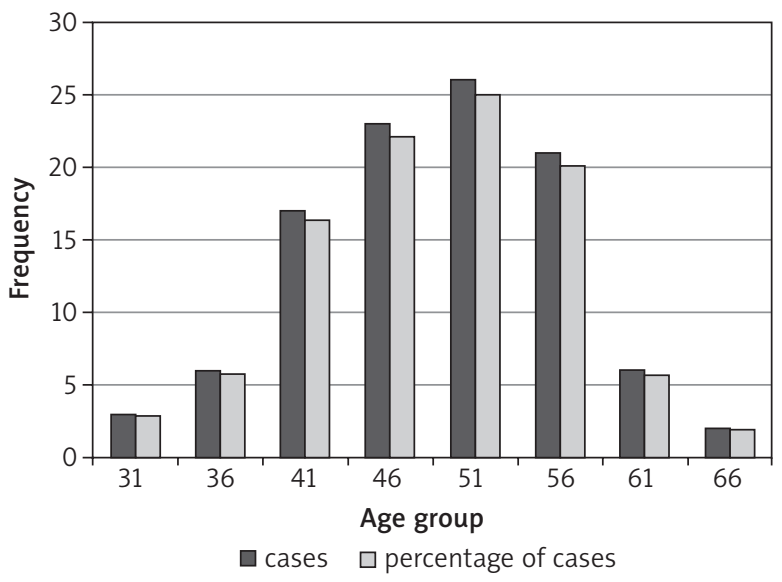

Fig. 1. Age distribution of 104 malignant ovarian endometriosis patients

analysis of ROC curve for prediction of malignant transformation of ovarian endometriosis are shown in Table 5.

When the diagnostic AUC corresponding to malignant lesions was 0.89 (95\% Cl: 0.84-0.94), the results were statistically significant $(p<0.001)$. When logitP was above 0.629 , the diagnostic sensitivity was 0.768 , and specificity was 0.883 . A detailed description of the data is given in Fig. 2.

Table 2. Statistically significant indicators between the groups

\begin{tabular}{|c|c|c|c|c|c|c|c|c|}
\hline \multirow[t]{2}{*}{ Project } & \multirow{2}{*}{$\begin{array}{c}\text { Age } \\
\text { (years) }\end{array}$} & \multirow{2}{*}{$\begin{array}{c}\text { Times of } \\
\text { pregnancy }\end{array}$} & \multirow[t]{2}{*}{ Packet size } & \multicolumn{2}{|c|}{ BMI $\left(\mathrm{kg} / \mathrm{m}^{2}\right)$} & \multicolumn{3}{|c|}{ Tumour fixation } \\
\hline & & & & $<25$ & $>25$ & no & Light & Serious \\
\hline $\begin{array}{l}\text { Research group } \\
(n=104)\end{array}$ & $49.57 \pm 9.47$ & $1.95 \pm 1.41$ & $9.12 \pm 4.12$ & $89(85.58)$ & $15(14.42)$ & $24(23.08)$ & $18(17.31)$ & $62(59.62)$ \\
\hline $\begin{array}{l}\text { Control group } \\
(n=104)\end{array}$ & $42.53 \pm 10.47$ & $1.05 \pm 0.51$ & $6.83 \pm 2.14$ & $100(96.15)$ & $4(3.8)$ & $35(33.33)$ & $28(26.92)$ & $41(39.74)$ \\
\hline$P$ & $<0.001$ & $<0.001$ & $<0.001$ & $<0$. & & & 0.014 & \\
\hline \multirow[t]{2}{*}{ Project } & \multicolumn{2}{|c|}{ Whether menopause } & \multicolumn{2}{|c|}{ Course of disease } & \multicolumn{2}{|c|}{ Vaginal bleeding } & \multicolumn{2}{|c|}{ Dysmenorrhea } \\
\hline & yes & no & $<8$ & $\geq 8$ & yes & no & yes & no \\
\hline $\begin{array}{l}\text { Research group } \\
(n=104)\end{array}$ & $43(41.35)$ & $61(58.65)$ & $70(67.31)$ & $34(32.69)$ & $20(19.23)$ & $84(80.77)$ & $29(27.88)$ & $75(72.12)$ \\
\hline $\begin{array}{l}\text { Control group } \\
(n=104)\end{array}$ & $11(10.26)$ & 93 (89.74) & $104(100.0)$ & $0(0.00)$ & $3(2.53)$ & $101(97.47)$ & $49(46.84)$ & $55(53.16)$ \\
\hline$P$ & $<0$ & & & & & 001 & & \\
\hline \multirow[t]{2}{*}{ Project } & \multicolumn{2}{|c|}{ Uterine myoma } & \multicolumn{2}{|c|}{ Endometrial carcinoma } & \multicolumn{2}{|c|}{ Family tumour history } & \multicolumn{2}{|c|}{ History of breast disease } \\
\hline & yes & no & yes & no & yes & no & yes & no \\
\hline $\begin{array}{l}\text { Research group } \\
(n=104)\end{array}$ & $43(41.35)$ & $61(58.65)$ & $7(6.73)$ & 97 (93.27) & $10(9.62)$ & $94(90.38)$ & $6(5.77)$ & $98(94.23)$ \\
\hline $\begin{array}{l}\text { Control group } \\
(n=104)\end{array}$ & $8(7.69)$ & $96(92.31)$ & $0(0.00)$ & 104(100.0) & $1(1.28)$ & 103(98.72) & $0(0.00)$ & 104(100.0) \\
\hline$P$ & & & & & & 05 & & \\
\hline \multirow[t]{2}{*}{ Project } & \multicolumn{2}{|c|}{ Thyroid diseases } & \multicolumn{2}{|c|}{ Multiple endometriosis } & & & & \\
\hline & yes & no & yes & no & & & & \\
\hline $\begin{array}{l}\text { Research group } \\
(n=104)\end{array}$ & $14(13.46)$ & $90(86.54)$ & 79 (75.96) & $25(24.04)$ & & & & \\
\hline $\begin{array}{l}\text { Control group } \\
(n=104)\end{array}$ & $3(2.53)$ & 101 (97.47) & $26(25.32)$ & $78(74.68)$ & & & & \\
\hline$P$ & \multicolumn{2}{|c|}{0.005} & \multicolumn{2}{|c|}{$<0.001$} & & & & \\
\hline
\end{tabular}


Table 3. Single factor logistic regression analysis results and ROC curve analysis

\begin{tabular}{|c|c|c|c|c|c|c|c|c|c|c|c|}
\hline \multirow[t]{2}{*}{ Project } & \multirow[t]{2}{*}{ Wald $\chi^{2}$} & \multirow[t]{2}{*}{$P$} & \multirow[t]{2}{*}{ OR } & \multicolumn{2}{|c|}{$95 \% \mathrm{Cl}$ for OR } & \multirow[t]{2}{*}{ AUC } & \multicolumn{2}{|c|}{$95 \% \mathrm{Cl}$ for AUC } & \multirow[t]{2}{*}{ Cut off } & \multirow[t]{2}{*}{ Sen } & \multirow[t]{2}{*}{ Sep } \\
\hline & & & & Upper & Lower & & Lower & Upper & & & \\
\hline Age & 18.231 & $<0.001$ & 1.075 & 1.040 & 1.111 & 0.70 & 0.62 & 0.78 & 48.5 & 0.577 & 0.744 \\
\hline $\begin{array}{l}\text { Times } \\
\text { of pregnancy }\end{array}$ & 22.004 & $<0.001$ & 2.776 & 1.812 & 4.252 & 0.72 & 0.64 & 0.79 & 1.5 & 0.606 & 0.872 \\
\hline Tumor size & 16.031 & $<0.001$ & 1.237 & 1.115 & 1.373 & 0.67 & 0.59 & 0.75 & 8.30 & 0.548 & 0.831 \\
\hline $\mathrm{BMI}$ & 4.872 & 0.027 & 4.213 & 1.175 & 15.108 & & & & & & \\
\hline $\begin{array}{l}\text { Whether } \\
\text { menopause }\end{array}$ & 35.454 & $<0.0001$ & 0.081 & 0.035 & 0.185 & 0.71 & 0.63 & 0.78 & yes & 0.413 & 1.000 \\
\hline $\begin{array}{l}\text { Course } \\
\text { of disease }\end{array}$ & 6.073 & 0.014 & 1.401 & 1.071 & 1.831 & 0.85 & 0.75 & 0.95 & 8.25 & 0.739 & 1.000 \\
\hline $\begin{array}{l}\text { Vaginal } \\
\text { bleeding }\end{array}$ & 8.539 & 0.003 & 9.167 & 2.074 & 40.513 & 0.58 & 0.50 & 0.67 & yes & 0.818 & 0.997 \\
\hline Dysmenorrhea & 6.873 & 0.009 & 0.439 & 0.237 & 0.812 & 0.60 & 0.51 & 0.68 & no & 0.474 & 0.721 \\
\hline $\begin{array}{l}\text { Thyroid } \\
\text { diseases }\end{array}$ & 5.300 & 0.021 & 5.911 & 1.302 & 26.831 & 0.55 & 0.47 & 0.64 & yes & 0.865 & 0.974 \\
\hline Uterine myoma & 20.704 & $<0.001$ & 8.459 & 3.372 & 21.220 & 0.67 & 0.59 & 0.75 & yes & 0.413 & 0.923 \\
\hline $\begin{array}{l}\text { Multiple } \\
\text { endometriosis }\end{array}$ & 43.874 & $<0.0001$ & 0.098 & 0.049 & 0.195 & 0.75 & 0.68 & 0.83 & yes & 0.760 & 0.744 \\
\hline Tumor fixation & 4.651 & 0.31 & 2.167 & 1.073 & 4.374 & 0.60 & 0.51 & 0.68 & yes & 0.769 & 0.333 \\
\hline
\end{tabular}

Table 4. Multivariate logistic regression analysis of EAOC

\begin{tabular}{|c|c|c|c|c|c|c|c|}
\hline \multirow[t]{2}{*}{ Project } & \multirow[t]{2}{*}{$b$} & \multirow[t]{2}{*}{ Stb } & \multirow[t]{2}{*}{ Wald $\chi^{2}$} & \multirow[t]{2}{*}{$P$} & \multirow[t]{2}{*}{ OR } & \multicolumn{2}{|c|}{$95 \% \mathrm{Cl}$ for $\mathrm{OR}$} \\
\hline & & & & & & Upper & Lower \\
\hline Constant term & -4.016 & 0.721 & 30.999 & $<0.001$ & & & \\
\hline Time of pregnancy & 0.934 & 0.253 & 13.660 & $<0.001$ & 2.544 & 1.550 & 4.174 \\
\hline Packet size & 0.185 & 0.069 & 7.307 & 0.007 & 1.204 & 1.052 & 1.377 \\
\hline $\begin{array}{l}\text { Multiple } \\
\text { endometriosis }\end{array}$ & 2.267 & 0.427 & 28.184 & $<0.001$ & 9.650 & 4.179 & 22.285 \\
\hline Uterine myoma & 1.568 & 0.555 & 7.975 & 0.005 & 4.798 & 1.616 & 14.250 \\
\hline
\end{tabular}

Table 5. Logistic regression equation analysis of ROC curve for prediction of malignant transformation of ovarian endometriosis

\begin{tabular}{|c|c|c|c|c|c|c|c|c|}
\hline & \multirow{2}{*}{ AUC } & \multirow{2}{*}{ Stb } & \multirow{2}{*}{$P$} & \multicolumn{2}{|c|}{$95 \% \mathrm{Cl}$ for $\mathrm{AUC}$} & \multirow{2}{*}{ Cut off } & \multirow{2}{*}{ Sen } & \multirow{2}{*}{ Sep } \\
\hline & & & & Lower & Upper & & & \\
\hline logitP & 0.89 & 0.03 & $<0.001$ & 0.84 & 0.94 & 0.629 & 0.768 & 0.883 \\
\hline
\end{tabular}

\section{Discussion}

In recent years, both the incidence of endometriosis and malignant transformation of endometriosis have been increasing. Due to the limitations caused by tissue sampling and tumour tissue degradation of ectopic endometrial tissue samples, it is difficult to accurately estimate the actual endometriosis malignant transformation rate. The MOE transformation rate of 1.61\% seen in our study is in agreement with the previous work of Vaima et al. [4], who described a transformation rate of $0.7-1.6 \%$.

The ovary is the most common location of endometriosis, and is also the most common location of MOE. The common pathological types of MOE were clear cell carcinoma and endometrial cancer [5]. According to an analysis among normal subjects, ovarian cancer patients and patients with borderline ovarian tumours, Pearce et al. [6] found EMT was a significant risk factor for low grade serous adenocarcinoma, endometrial adenocarcinoma (EAC), and clear cell carcinoma (CCC), but showed no connection with mucinous ovarian carcinoma, or high grade serous carcinoma, or any borderline tumours.

In our research, the number of EAOC patients was 104 , the number of ovarian clear cell carcinoma and ovarian endometrial adenocarcinoma patients was 86 (82.69\%), 18 EAOC patients had other diagnoses (17.31\%). The results were consistent with previous literature reporting that the major histological types undergoing MOE transformation were CCC and EAC. 
Previous work demonstrated that the risk of malignancy was further increased in postmenopausal endometriosis patients. For example, one study reported that, of $11 \mathrm{MOE}$ transformation patients, 8 were postmenopausal [7]. In the a paper by Shen YangMei, the proportion of EAOC patients was $59.2 \%$, the age range of patients was between 44 and 57 years, and the median age was 49 years [8]. In our research, the percentage of post-menopausal patients in all 104 EAOC patients was $41.35 \%$. The percentage of patients aged between 40 and 60 years old was $81.73 \%$, the average age of patients were $49.57 \pm 9.47$ years. Therefore, in our study, ovarian endometriosis affected both perimenopausal and postmenopausal patients approximately equally.

The research of Erzen et al. has shown that cancer rate increases with the duration of endometriosis, the study from the Swedish National Cancer Institute including 20686 patients (average age 38.8 years) with endometriosis revealed that the risk of malignant transformation increased with duration of disease. The average age of malignant transformation in the study was 52.3 years [9]. In our research, among the 104 EAOC patients, the number of patients with a history of ovarian endometriosis (OEMs) was 38 (36.54\%), the longest duration of OEMs disease was 23 years, and the average duration of OEMs disease was 10 years. The ROC curve of EAOC disease was 0.85 , which indicated that malignant risk increased with OEMs disease duration.

It was well known that a high concentration of oestrogen is one of the contributory factors to endometriosis. Gumiskey et al. [10] found that the oestrogen receptor densities of premenopausal and postmenopausal endometriosis patients were similar, while the endometriosis malignant transformation in postmenopausal patients could be activated by high oestrogen concentrations. The oestrogen in postmenopausal women mainly came from exogenous hormone intake or peripheral conversion of adrenal androstenedione in adipose tissue. Therefore, if endogenous oestrogen levels in postmenopausal obese endometriosis patients were high, even without exogenous oestrogen stimulation, the rate of malignant transformation could also be increased [11]. After menopause, if the BMI value is elevated, this could indicate increased risk of OEM malignant transformation. Our data also revealed that thyroid disease is another risk factor for malignant transformation, although the mechanism is not clear and requires further study. Notably, this association has not previously been reported in the literature.

Multivariate logistic regression suggested that times of pregnancy, tumour size, myoma of uterine, and multiple foci of endometriosis were independent risk factors for EAOC. The ROC curve of logistic regression was 0.89. When logitP was over 0.629, the diagnostic sensitivity was over 0.768 , and the specificity was over 0.883 , which suggests higher prediction efficiency. In

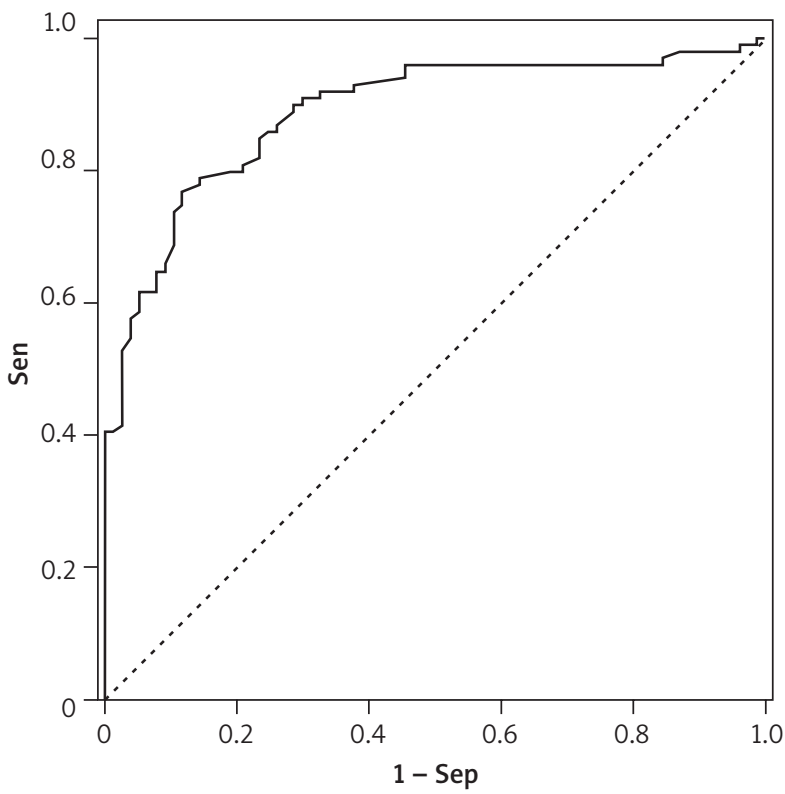

Fig. 2. ROC curve

our results, the mean cyst size in MOE patients was 9.12 $\pm 4.12 \mathrm{~cm}$. Other studies have suggested that if the cyst diameter was over $8 \mathrm{~cm}$, MOE risk could increase up to $870 \%$ [12].

Blumenfeld et al. [13] showed that when patients with endometriosis were exposed to excessive hormone therapy, malignant transformation risk was significantly increased, suggesting oestrogen replacement therapy could be a risk factor for MOE [14]. Uterine fibroid disease is associated with excessive oestrogen stimulation, and in our report uterine fibroids were an independent risk factor for MOE. This indirectly implicates that the level of oestrogen could be high with MOE. There were some reports about multiple foci of endometriosis being an independent risk factor for EAOC, and the ectopic endometrial cells growth and invasion tendency of EAOC patients were more obvious.

Some research suggested that early menarche, short menstruation period, late menopause, and higher pregnancy frequency increased risk of endometriosis and malignant transformation of endometriosis. Melin et al. found the prevalence of malignant transformation of endometriosis increases with longer infertility time, the longer the duration of endometriosis, or the lower age of onset of endometriosis [15]. In our research, comparing EAOC patients with control subjects, there were no statistically significant effects of age of menarche, menstruation period, frequency of menstrual period, age of menopause, or delivery times. It was suggested that higher pregnancy frequency was an independent risk factor for EAOC, perhaps implying that abnormal endometrial counter-current transfer caused by abortion, or hormone level changes, or inflammation might be the reason for the occurrence of malignant transformation of endometriosis. For example, the re- 
search of Banz et al. suggested a connection between inflammation and malignant transformation of endometriosis [16].

In conclusion, early age of onset, long duration of disease, obesity, dysmenorrhea, perimenopause and menopause, irregular vaginal bleeding, gynaecological examination of tumour fixation, tumour diameter over $80 \mathrm{~mm}$, rapid increase in tumour size, the number of abortions, myoma of uterus, thyroid disease, and multiple foci of endometriosis were risk factors for MOE transformation. These risk factors have the potential to be predictive clinical markers.

To optimise early diagnosis and treatment, and to improve patient morbidity and mortality, it will be necessary to implement a risk-assessment score into the existing logistical framework, with close monitoring and follow-up to ensure changes are implemented.

\section{Disclosure}

Authors report no conflict of interest.

\section{References}

1. Smith HO, Arias-Pulido H, Kuo DY. GPR30 predicts poor survival for ovarian cancer. Gynecol Oncol 2009; 114: 465-471

2. Sampson JA. Endometrial carcinoma of the ovary arising in endometrial tissue in that organ. Arch Surg 1925; 10: 1-12.

3. Scott B. Malignant Changesin Endometriosis. Obstet Gynecol 1953; 2: 283-289.

4. Vaima R, Rollason T, Gupta JK. Endometriosis and the neoplastic process. Reproduction 2004; 127: 293-304.

5. Boruban MC, Jaishuen A. Sirisabya N. Ovarian endometriosis associated with carcinoma and sarcoma, case report. Eur J Gynaecol Oncol 2008; 29: 393-396.

6. Pearce CL., Templeman C, Rossing MA. Association between endometriosis and risk of histological subtypes of ovarian cancer: a pooled analysis of case-control studies. Lancet Oncol 2012; 13: 385-394

7. Engin O. Prevalence of endometriosis in malignant epithelial ovary tumours. Eur J Obstet Gynecol Reprod Biol 2003; 109, 97-101.

8. Shen Yang-Mei, Wu XL, Xu L, Huang Q, et al. Malignant transformation of ovarian endometriosis: a clinicopathologic analysis of 49 cases. Chinese J Cancer 2008; 27: 1106-1110.

9. Erzen M, Rakar S, Klancnik B. Endometriosis associated ovarian carcinoma (EAOC), an entity distinct from other ovarian carcinomas as suggested by a nested case-control study. Gynecol Oncol 2001; 83: 100-108.

10. Gumiskey J. Whyte P. Kelehan P. A detailed morphologic and immunohistochemical comparison of pre- and postmenopausal endometriosis. J Clin Pathol 2008; 61: 455-459.

11. Magtibay PM. Heppell J.Leslie KO. Endometriosis-associated invasive adenocarcinoma involving the rectum in a postmenopausal female, report of a case. Dis Colon Rectum 2001; 44: 1530-1533.

12. Xiao Xi-Rong, et al. Prediction method research of malignant transformation of ovarian endometriosis. Reproduction Contraception 2014; 34 : 367-370.

13. Blumenfeld Z. Hormonal suppressive therapy for endometriosis may not improve patient health. Fertil Steril 2004; 81: 487-492.

14. Benoit L. Amould L. Cheynel N, et al. Malignant extraovarian endometriosis, a review. Eur J Surg Oncol 2006; 32: 6-11.

15. Melin A, Sparén P, Persson I, Endometriosis and the risk of cancer with special emphasis on ovarian cancer. Hum Reprod 2006; 21: 1237-1242.

16. Banz C, Ungethuem U, Kuban RJ, et al. The molecular signature of endometriosis-assoeiated endometrioid ovarian cancer difiers significanfly from endometriosis independent endometrioid ovarian cancer. Fertil Steril 2010; 94: 1212-1217. 